\title{
Optimized Sample-Processing Time and Peptide Recovery for the Mass Spectrometric Analysis of Protein Digests
}

\author{
Doris E. Terry, Edward Umstot, and Dominic M. Desideriołł \\ The Charles B. Stout Neuroscience Mass Spectrometry Laboratory, The University of Tennessee Center \\ for Health Science Memphis, Tennessee, USA
}

\begin{abstract}
Proteomics requires an optimized level of sample-processing, including a minimal sampleprocessing time and an optimal peptide recovery from protein digests, in order to maximize the percentage sequence coverage and to improve the accuracy of protein identification. The conventional methods of protein characterization from one-dimensional or two-dimensional gels include the destaining of an excised gel piece, followed by an overnight in-gel enzyme digestion. The aims of this study were to determine whether: (1) stained gels can be used without any destaining for trypsin digestion and mass spectrometry (MS); (2) tryptic peptides can be recovered from a matrix-assisted laser desorption/ionization (MALDI) target plate for a subsequent analysis with liquid chromatography (LC) coupled to an electrospray ionization (ESI) quadrupole ion trap MS; and (3) an overnight in-gel digestion is necessary for protein characterization with MS. These three strategies would significantly improve sample throughput. Cerebrospinal fluid (CSF) was the model biological fluid used to develop these methods. CSF was desalted by gel filtration, and CSF proteins were separated by two-dimensional gel electrophoresis (2DGE). Proteins were visualized with either silver, Coomassie, or Stains-All (counterstained with silver). None of the gels was destained. Protein spots were in-gel trypsin digested, the tryptic peptides were purified with ZipTip, and the peptides were analyzed with MALDI and ESI MS. Some of the samples that were spotted onto a wax-coated MALDI target plate were recovered and analyzed with ESI MS. All three types of stained gels were compatible with MALDI and ESI MS without any destaining. In-gel trypsin digestion can be performed in only 10-60 min for protein characterization with MS, the sample can be recovered from the MALDI target plate for use in ESI MS, and there was a $90 \%$ reduction in sample-processing time from overnight to ca. $3 \mathrm{~h}$. (J Am Soc Mass Spectrom 2004, 15, 784-794) (c) 2004 American Society for Mass Spectrometry
\end{abstract}

$\mathrm{T}$ The conventional method for protein characterization and identification from two-dimensional (2-D) gels involves the destaining of the excised gel pieces, followed by an overnight in-gel enzyme digestion and mass spectrometry (MS) [1-10]. Recently, 4 and $6 \mathrm{~h}$ in-gel trypsin digestions have been used for mass spectrometry (MS) analysis [7, 11].

Protein identification with matrix-assisted laser desorption/ionization-time of flight (MALDI-TOF) MS has

Published online April 2, 2004

Address reprint requests to Dr. D. E. Terry, Department of Biochemistry, Purdue University, 175 S. University Street, West Lafayette, IN 47907, USA. E-mail: terryd@purdue.edu

*Current address: Bindley Bioscience Center, Discovery Park, Purdue University, West Lafayette, IN 47907, USA.

tAlso at the Department of Neurology, The University of Tennessee Center for Health Science, Memphis, TN 38163, USA.

$\ddagger$ Also at the Department of Molecular Sciences, The University of Tennessee Center for Health Science, Memphis, TN 38163, USA. been enhanced by employing methods such as ZipTip (Millipore Corp., Bedford, MA) purification [5, 12-16] and by the use of a hydrophobic sample support for sample purification and sample delivery into the MS. The use of sample supports has been developed to improve detection sensitivity and to remove salts. Some of the polymer materials that have been used for hydrophobic surfaces on MALDI target plates include polytetrafluoroethylene (Teflon; [4, 17-19]), polyurethane [20], paraffin wax film [21], and polyethylene and polypropylene [22]. For routine MS analysis, a sample is processed for either MALDI or ESI MS, or it is "split" for a MALDI and ESI MS analysis. There is no published report on the recovery of tryptic peptides from a MALDI target plate. The aims of this study were to determine the compatibility of in-gel trypsin digestion of stained protein spots with MS, to evaluate the time necessary for in-gel trypsin digestion for protein characterization with MS, and to recover tryptic peptides from a MALDI target plate for subsequent analysis with ESI. 


\section{Experimental}

\section{CS Sample}

A human CSF sample was obtained after appropriate institutional approvals by lumbar puncture (courtesy of Dr N. M. Oyesiku, Emory University, Atlanta), frozen immediately with liquid nitrogen, and shipped on dry ice to Memphis. It was thawed, a cocktail of protease inhibitors [10 mM EDTA, $1 \mathrm{mM}$ phenylmethylsulfonyl fluoride (PMSF), Complete mini (Roche, Mannheim, Germany)] was added, and the CSF was stored $\left(-80^{\circ} \mathrm{C}\right)$ until analyzed.

\section{Desalting of Cerebrospinal Fluid}

CSF samples were desalted by Bio-Spin chromatography, as described by the manufacturer (Bio-Rad Laboratories, Hercules, CA,). Bio-gel P-6 (30 g, Bio-Rad Laboratories) was washed with the standard cycle of washing. A column with a gel-bed volume of $3.5 \mathrm{~mL}$ was prepared by pouring a slurry of Bio-gel P-6 in buffer (150 mM sodium chloride, $17.5 \mathrm{mM}$ sodium citrate, pH 7.0) into a $1 \times 10 \mathrm{~cm}$ column. The buffer in the column was exchanged $(3 \times)$ with deionized distilled water, and was centrifuged at $1000 \times g$ for $1 \mathrm{~min}$. Thawed CSF (1 mL) was applied to the Bio-Gel P-6 column, and was centrifuged $(1000 \times g, 4 \mathrm{~min})$. An aliquot $(10 \mu \mathrm{L})$ was removed from the desalted CSF for protein assay, and the remainder was stored $\left(-20^{\circ} \mathrm{C}\right)$.

\section{Protein Assay}

A Coomassie Plus Protein Assay Reagent Kit (Pierce, Rockford, IL) was used to measure the CSF protein content. The protein content of the original and desalted CSF was measured by the Pierce-modified Bradford method [23], using bovine serum albumin as the protein standard. CSF $(10 \mu \mathrm{L})$ was diluted (1:150, vol/vol) with water, and duplicate aliquots $(0.7 \mathrm{~mL})$ of diluted CSF, blank, and known concentrations of the standard, were measured. Coomassie Plus reagent $(0.7 \mathrm{~mL})$ was added to each tube, the contents were mixed, and the absorbance of the solution was measured at $595 \mathrm{~nm}$. The standards were plotted, and the CSF protein concentration was obtained.

\section{Two-Dimensional Gel Electrophoresis}

An appropriate volume of rehydration buffer [7 $\mathrm{M}$ urea, $2 \mathrm{M}$ thiourea, $2 \%$ CHAPS, $0.8 \%$ ampholyte $\mathrm{pH}$ 3-10 non-linear (NL), 0.02\% bromophenol blue, and $60 \mathrm{mM}$ dithiothreitol (DTT)] was added to desalted CSF (52$104 \mu \mathrm{L}$, contained $25-50 \mu \mathrm{g}$ protein) to make a total volume of $350 \mu \mathrm{L}$. The mixture was agitated $(1 \mathrm{~h}$, room temperature) with a vortex mixer (Vortex-Genie mixer, Fisher Scientific, Pittsburgh, PA). The mixture $(350 \mu \mathrm{L})$ was loaded onto an immobilized $\mathrm{pH}$ gradient (IPG) drystrip ( $\mathrm{pH}$ 3-10, NL, 18-cm, Amersham Biosciences,
Uppsala, Sweden). After rehydration (12 h), the proteins were focused with an isoelectric focusing (IEF) unit (IPGphor, Amersham Biosciences, San Francisco, CA), with a six-step program $(100 \mathrm{~V}$ for $2 \mathrm{~h}, 500 \mathrm{~V}$ for $1 \mathrm{~h}, 1000 \mathrm{~V}$ for $1 \mathrm{~h}, 2000 \mathrm{~V}$ for $2 \mathrm{~h}, 3500 \mathrm{~V}$ for $8 \mathrm{~h}$, and $8000 \mathrm{~V}$ for $7 \mathrm{~h}$ ). A limiting current (50 $\mu \mathrm{A}$ per strip) was maintained. After IEF, the strips were stored $\left(-80{ }^{\circ} \mathrm{C}\right)$ until they were analyzed with sodium dodecyl sulfate polyacrylamide gel electrophoresis (SDS-PAGE).

The IPG strips were equilibrated (10 min) with $2 \%$ (wt/vol) DTT in $4.2 \mathrm{~mL} / \mathrm{strip}$ of an equilibration solution [0.38 M Tris-base, $\mathrm{pH} 8.8,6 \mathrm{mM}$ urea, 2\% (wt/vol) SDS and 20\% (vol/vol) glycerol], and (10 min) with $2.5 \%$ (wt/vol) iodoacetamide in the equilibration solution. Each IPG strip was loaded onto a $12 \%$ acrylamide gel, which was sealed with $1 \%$ agarose in buffer (see below); and electrophoresed ( $200 \mathrm{~V}$ for $8 \mathrm{~h}$ ) in a ProteinPlus Dodeca Cell (Bio-Rad Laboratories) in a buffer (25 $\mathrm{mM}$ Tris, $190 \mathrm{mM}$ glycine and 0.1\% SDS).

\section{Protein Staining}

Three different staining methods (silver, Coomassie blue, and Stains-All counterstained with silver) were used to visualize the proteins. (1) The 2DGE gels were stained with silver nitrate, employing a slight modification of Amersham Biosciences' procedure [24]. The gels were fixed $(1 \mathrm{~h})$ in an aqueous solution of $40 \%$ ethanol:10\% acetic acid (vol/vol) for $1 \mathrm{~h}$ with gentle shaking on a Maxi Rotator (Lab-Line Instruments, Inc., Melrose Park, IL). They were incubated $(30 \mathrm{~min})$ in $100 \mathrm{~mL} / \mathrm{gel}$ of an aqueous sensitizing solution (30\% ethanol, $0.2 \%$ sodium thiosulfate, $6.8 \%$ sodium acetate), and were washed with three changes of water ( $5 \mathrm{~min}$ each). Thereafter, the gels were incubated $(20 \mathrm{~min}$ ) in $0.25 \%$ (wt/vol) silver nitrate solution. They were washed twice with water $(1 \mathrm{~min}$ each), and were incubated in $100 \mathrm{~mL} / \mathrm{gel}$ of a developing solution [2.5\% (wt/vol) sodium carbonate, $0.015 \%$ (vol/vol) formaldehyde]. The developer was changed whenever it turned brown or when a smokey precipitate appeared. After the desired staining intensity was achieved (usually $4 \mathrm{~min}$ ), the development was stopped by replacing the solution with $100 \mathrm{~mL} /$ gel of $5 \%$ (vol/vol) acetic acid, and the solution was gently agitated $(10 \mathrm{~min})$. The gels were washed with water $3 \times$ (5 min each) and were stored. (2) For Coomassie blue, the gels were fixed in an aqueous solution as in (1), and were incubated $(1 \mathrm{~h})$ with GelCode ${ }^{\circledR}$ Blue stain reagent (Pierce, Rockford, IL). They were rinsed with water until the background was completely colorless. (3) For Stains-All, the gels were fixed in $25 \%$ isopropanol, stained with Stains-All, and counterstained with silver nitrate, according to the method of Goldberg and Warner [25]. Briefly, gels were fixed in $25 \%$ (vol/vol) isopropanol $(150 \mathrm{~mL})$ on a shaker $(50 \mathrm{~min})$. The isopropanol was replaced with Stains-All solution ([150 mL], $30 \mathrm{mM}$ Tris, $7.5 \%$ formamide [vol/vol], $25 \%$ isopropanol [vol/vol], adjusted to $\mathrm{pH} 8.8$ with $\mathrm{HCl}$, followed by addition of $0.025 \%$ Stains-All [wt/vol]). Because Stains- 


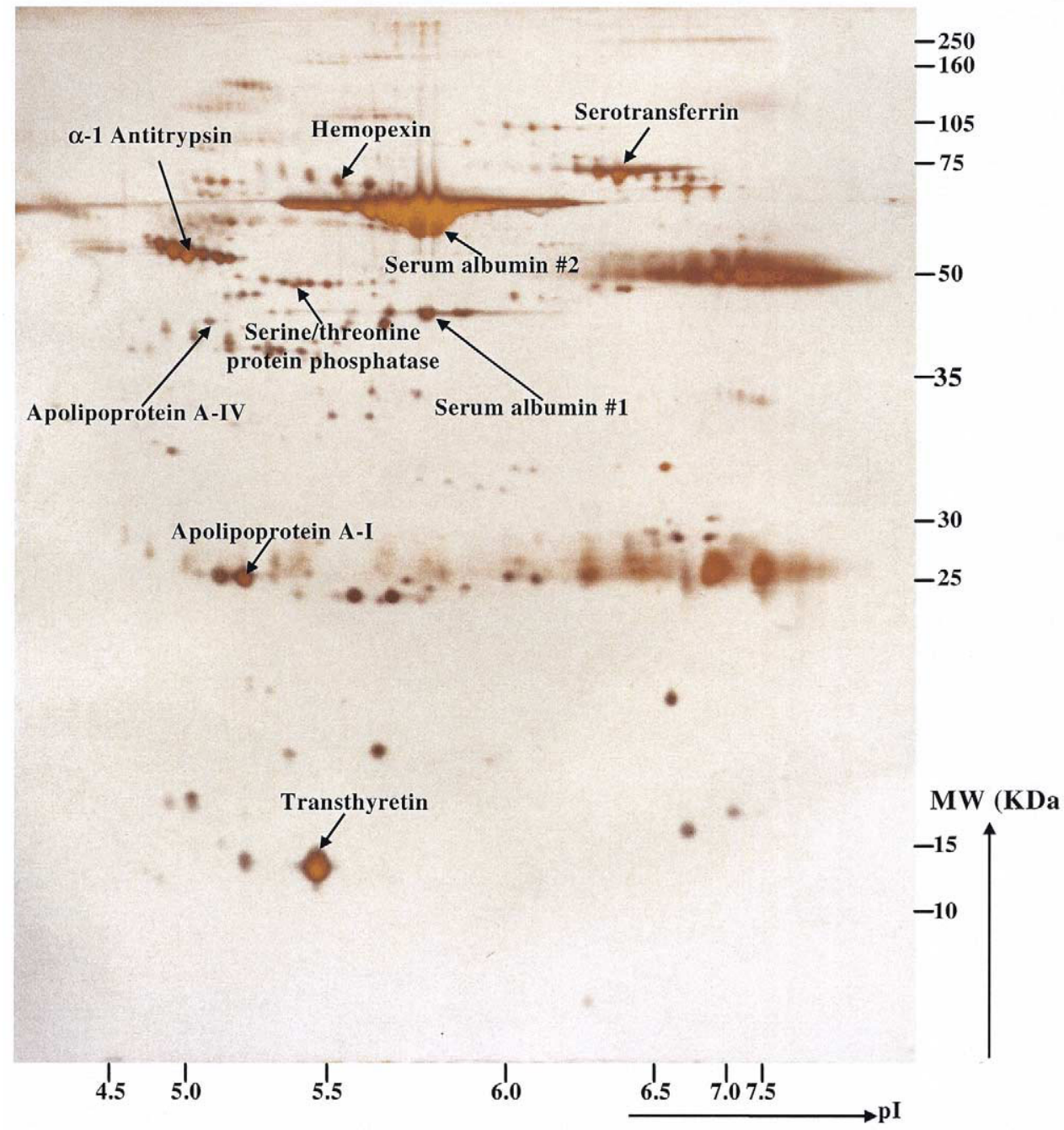

Figure 1. 2-D map of CSF proteins. CSF proteins were separated on a $\mathrm{pH}$ 3-10 non-linear IPG strip, followed by $12 \%$ SDS-PAGE. The gels were stained with silver nitrate. The nine protein spots that were selected for MS analysis are marked.

All is photosensitive, the gels were incubated $(2 \mathrm{~h}$, room temperature) in light-tight containers (i.e., covered with aluminum foil) on a shaker. The gels were destained with $25 \%$ isopropanol until the background became clear (approximately $1 \mathrm{~h}$ ). They were rinsed $(3 \times)$ with water, and were silver-stained as described above.

\section{Image Analysis}

The stained 2-D gels were scanned at 300-dpi resolution with an Epson Expression 800 scanner (Epson, Singapore) and Photoshop software (version 6.2.1, Adobe Systems Inc., San Jose, CA). The gel images were saved as .tiff files, and were analyzed with PDQuest 2-D gel analysis software (version 6.2, Bio-Rad Laboratories).

\section{In-Gel Trypsin Digestion}

The in-gel digestion methods were a modification of Gharahdaghi et al. [1]. Each selected spot was excised (with a cut pipette tip) from a wet, stained 2-D gel, and the gel pieces were placed into a siliconized polypropylene microcentrifuge tube $(0.6 \mathrm{~mL})$. Some of the gel pieces were destained with a freshly prepared destaining solution $(20 \mu \mathrm{L})$ that contained $30 \mathrm{mM}$ potassium ferricyanide and $100 \mathrm{mM}$ sodium thiosulfate. The gel pieces destained in $<2 \mathrm{~min}$. The destaining solution was removed, and the gel pieces were washed with $50 \mu \mathrm{L}$ water (5-7 times) until the yellow color disappeared. The gel pieces were washed $(2 \times)$ with $50 \mu \mathrm{L}$ of $50 \%$ acetonitrile $(\mathrm{ACN}): 50 \% 200 \mathrm{mM}$ ammonium bicarbonate for $5 \mathrm{~min}$, dehydrated with $50 \mathrm{uL}$ of $100 \%$ ACN until the gel turned opaque white, and dried in a vacuum centrifuge for 30 min (Eppendorf Vacufuge; Eppendorf-Netheler-Hinz $\mathrm{GmbH}$, Hamburg, Germany). Some of the gel pieces were not destained, but were washed (2×) with $50 \mu \mathrm{L}$ of $50 \%$ ACN:50\% $200 \mathrm{mM}$ ammonium bicarbonate (5 min), dehydrated (50 $\mu \mathrm{L} \mathrm{100 \%} \mathrm{ACN)} \mathrm{until} \mathrm{the} \mathrm{gel} \mathrm{turned} \mathrm{opaque}$ white, and dried in a vacuum centrifuge $(30 \mathrm{~min})$. The gel pieces were rehydrated in 5-10 $\mu \mathrm{L}$ of $50 \mathrm{mM}$ ammonium 
Table 1. Sequence coverage vs digestion time of destained gel plugs

\begin{tabular}{lcc}
\hline (A) MALDI & & \\
\hline \hline $\begin{array}{l}\text { Duration of } \\
\text { trypsin } \\
\text { digestion }\end{array}$ & $\begin{array}{c}\text { Sequence } \\
\text { coverage (\%) }\end{array}$ & $\begin{array}{c}\text { No. of } \\
\text { peptides } \\
\text { matched }\end{array}$ \\
\hline \hline 10 min & $85 \pm 0$ & $12 \pm 1$ \\
30 min & $86 \pm 1$ & $11 \pm 1$ \\
$1 \mathrm{~h}$ & $100 \pm 0$ & $14 \pm 0$ \\
$2 \mathrm{~h}$ & $85 \pm 6$ & $10 \pm 1$ \\
$4 \mathrm{~h}$ & $88 \pm 4$ & $11 \pm 1$ \\
Overnight & $80 \pm 11$ & $8 \pm 2$ \\
\hline \hline (B) ESI & & No. of \\
\hline \hline Duration of & & peptides \\
trypsin & matched \\
digestion & Sequence & $14 \pm 3$ \\
\hline \hline $1 \mathrm{~h}$ & $20 \pm 3$ & $15 \pm 1$ \\
$2 \mathrm{~h}$ & $21 \pm 1$ & $14 \pm 1$ \\
$4 \mathrm{~h}$ & $21 \pm 1$ & $16 \pm 2$ \\
\hline Overnight & $21 \pm 4$ & \\
\hline
\end{tabular}

TR (A) or serum albumin (B) spots were destained, in-gel digested with trypsin at various time intervals, and the digest was analyzed with MS. Those data are mean \pm s.d., $n=2-4$.

bicarbonate $\left(37{ }^{\circ} \mathrm{C}, 4 \mathrm{~min}\right)$, an equivalent volume (5-10 $\mu \mathrm{L}$ ) of trypsin (Promega, Madison, WI) solution (8.35 $\mathrm{ng} / \mu \mathrm{L}$ in $50 \mathrm{mM}$ ammonium bicarbonate) was added, and digestion was performed (10 $\mathrm{min}, 30 \mathrm{~min}, 1 \mathrm{~h}, 2 \mathrm{~h}, 4 \mathrm{~h}$, and overnight). After digestion, the peptides were extracted (3×) with $50 \mu \mathrm{L}$ of $60 \% \mathrm{ACN}$ in $5 \%$ TFA (vol/vol) by sonication $(10 \mathrm{~min})$. The supernatants were pooled, and were dried in a vacuum centrifuge.

\section{MALDI-TOF MS Analysis}

Within a day prior to MALDI MS analysis, the dried tryptic digest samples were reconstituted $(10 \mu \mathrm{L}, 0.1 \%$ TFA), and were purified with a ZipTip ${ }_{\mathrm{C} 18}$ (Millipore, Billerica, MA) [15, 26], using the procedure recommended by the manufacturer. Because hydrophobic surfaces have been shown to enhance protein identification [10, 11], a wax hydrophobic surface was used as the standard. A solution $(50 \mathrm{mg} / \mathrm{mL})$ of paraffin wax (Surgipath Medical Industries, Richmond, IL) dissolved in chloroform was smoothed onto a stainless steel MALDI target plate (PerSeptive Biosystems, Inc., Framingham, MA) with a Caliber ${ }^{\mathrm{TM}}$ cotton-tipped applicator (Allegiance Healthcare Corporation, McGaw Park, IL) to provide a hydrophobic surface. The plate was allowed to dry ( $5 \mathrm{~min}$, room temperature). The purified peptides were eluted from the ZipTip onto a wax-coated stainless steel MALDI target plate with $2 \mu \mathrm{L}$ of $\alpha$-cyano-4-hydroxycinnamic acid (Fluka Chemie $\mathrm{GmbH}$, Steinheim, Germany) solution $(2 \mathrm{mg} / \mathrm{mL}$ in $50 \%$ acetonitrile: $0.1 \%$ TFA ( $\mathrm{vol} / \mathrm{vol})$. The solution was allowed to dry (room temperature), and a spot (diameter $=1.25 \mathrm{~mm}$ ) was produced. The tryptic peptides were analyzed with a Voyager-DE
Table 2. Stained and destained gel spots

\begin{tabular}{lcc}
\hline MALDI & $\begin{array}{c}\text { Soquence } \\
\text { coverage (\%) }\end{array}$ & $\begin{array}{c}\text { peptides } \\
\text { matched }\end{array}$ \\
\hline \hline Stained gel piece & 69 & 6 \\
$\begin{array}{l}\text { Destained gel piece } \\
\text { ESI }\end{array}$ & 69 & 5 \\
Stained gel piece & 88 & 10 \\
Destained gel piece & 78 & 9 \\
\hline
\end{tabular}

TR spots were obtained from replicates of silver-stained gels, and were in-gel trypsin digested overnight $(n=2)$.

RP MALDI-TOF mass spectrometer (PerSeptive Biosystems/Applied Biosystems, Inc., Framingham, MA). Mass spectra were recorded in the positive-ion, delayed-extraction (DE) mode. All spectra were acquired with $20 \mathrm{kV}$ accelerating voltage, $57 \%$ grid voltage, 1.08 mirror voltage ratio, $0.07 \%$ guide wire, 150 ns delayed extraction time, and $300 \mathrm{Da}$ low-mass gate. All spectra were internally mass-calibrated with the protonated molecule ions, $(\mathrm{M}+\mathrm{H})^{+}$, of trypsin autodigestion peptides $(\mathrm{m} / \mathrm{z} 515.33,842.51$, and 2211.10$)$ and matrix peaks $(\mathrm{m} / \mathrm{z} 379.11$ and 568.14$)$.

\section{Comparing MALDI Target Plate Surfaces}

The MS characterization of a model protein digest, transthyretin (TR), on a wax-coated stainless steel MALDI target plate was compared to other MALDI target plates: the AnchorChip (Bruker Daltonics, Bremen, Germany, adapted to the Voyager) and a plain stainless plate. A sample pool was made from the TR protein spot excised from four similarly prepared silver-stained 2-D gels, with $50 \mu \mathrm{g}$ CSF protein loaded per gel. The four spots were pooled, and were in-gel trypsin digested. Peptides were extracted $(3 \times)$ with $150 \mu \mathrm{L}$ (rather than $50 \mu \mathrm{L}$ ) of an aqueous solution of $60 \%$ ACN:5\% TFA (vol/vol), the extract was dried, reconstituted in $50 \mu \mathrm{L}$ of $0.1 \%$ TFA, and purified with a ZipTip, $10 \mu \mathrm{L}$ at a time. The peptides were eluted from the

Table 3. Sequence coverage vs. digestion time

\begin{tabular}{lcc}
\hline Protein & $1 \mathrm{~h}$ incubation & Overnight incubation \\
\hline \hline Transthyretin & $11 \pm 0 / 82 \pm 2$ & $9 \pm 0 / 75 \pm 0$ \\
Apolipoprotein A-I & $13 \pm 1 / 52 \pm 3$ & $8 \pm 2 / 29 \pm 3$ \\
Apolipoprotein A-IV & $19 \pm 0 / 46 \pm 2$ & $19 \pm 2 / 46 \pm 5$ \\
Serum albumin (1) & $17 \pm 1 / 34 \pm 2$ & $16 \pm 1 / 34 \pm 0$ \\
Serine/Threonine & $6 \pm 0 / 12 \pm 0$ & $3 \pm 1 / 7 \pm 2$ \\
$\quad$ protein & & \\
$\quad$ phosphatase & $11 \pm 3 / 42 \pm 7$ & $14 \pm 3 / 42 \pm 6$ \\
$\alpha-1$ Antitrypsin & $12 \pm 1 / 31 \pm 2$ & $9 \pm 1 / 26 \pm 2$ \\
Hemopexin & $34 \pm 1 / 59 \pm 3$ & $33 \pm 0 / 57 \pm 2$ \\
Serum albumin (2) & $34 \pm 0.46 \pm 2$ & $31 \pm 2 / 46 \pm 4$ \\
Serotransferrin & $35 \pm 1 / 56 \pm 3$ & \\
\hline
\end{tabular}

No. peptides/\% protein coverage.

The protein containing spots were excised from silver-stained 2-D gels, the stained gel plugs were in-gel trypsin digested, and the tryptic peptides were processed for MALDI-TOF MS analysis as described in the Experimental section (Mean \pm s.d., $n=3-5$ ). 

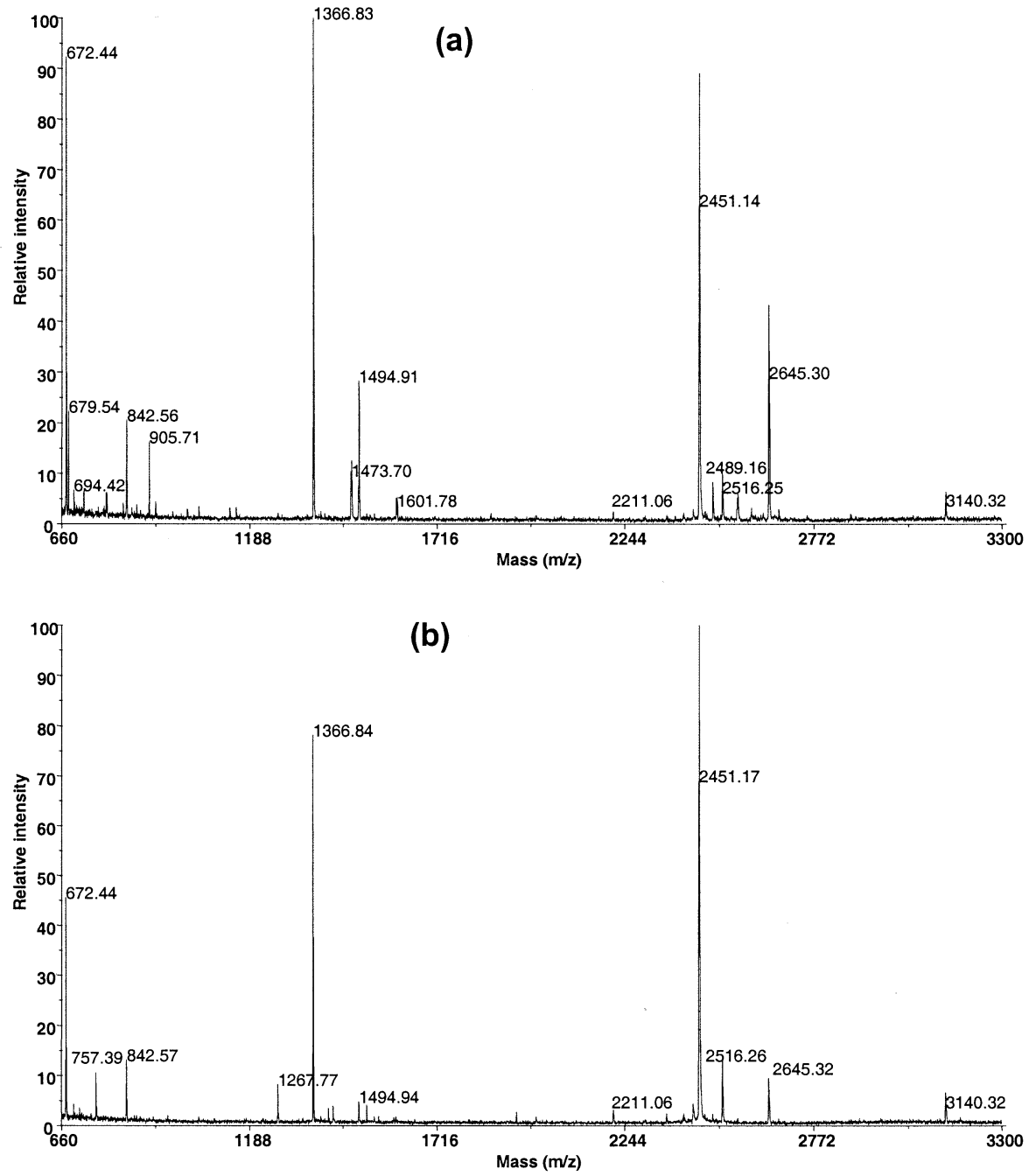

Figure 2. Comparison of MALDI spectra obtained after $1 \mathrm{~h}$ versus overnight digestion of transthyretin. The TR spot was excised from silver-stained 2-D gels ( $25 \mu \mathrm{g}$ CSF protein/gel). The destained TR spot was in-gel trypsin digested for $1 \mathrm{~h}$ (a) or overnight (b), and was analyzed on a wax-coated stainless MALDI target plate.

ZipTip with $4 \mu \mathrm{L}$ of $5 \%$ ACN:0.1\% TFA (vol/vol) followed by $2 \times 4 \mu \mathrm{L}$ of $50 \%$ ACN:0.1\% TFA, and the pooled eluate was concentrated to ca. $30 \mu \mathrm{L}$ (that eluate was designated the "TR stock"). The TR stock was diluted (1/2 to $1 / 50)$ with $5 \% \mathrm{ACN} / 0.1 \%$ TFA, and each dilution was mixed 1:1 (vol/vol) with a CHCA solution, and spotted onto a MALDI target plate. For wax-coated stainless steel and anchor chip MALDI target plates, 1 part TR dilution was mixed with 1 part of $4 \mathrm{mg} \mathrm{CHCA} / \mathrm{mL}$ in 50\% acetonitrile:0.1\% TFA (vol/ vol). Therefore, the concentration of CHCA was 2 $\mathrm{mg} / \mathrm{mL}$ in the spotted sample on the AnchorChip and wax-coated stainless steel MALDI target plates. For a stainless steel MALDI target plate, $8 \mathrm{mg}$ CHCA/mL was used with a CHCA concentration of $4 \mathrm{mg} / \mathrm{mL}$ in the spotted sample. Each CHCA concentration was optimized for each particular MALDI target plate. Two microliters of each solution was spotted. The diameters of the dried spots were $1.25,2$, and $3 \mathrm{~mm}$ for wax- coated, anchor chip, and stainless MALDI target plates, respectively.

\section{Protein Database Search}

The matching of the experimental tryptic peptide mass with the in silico-derived tryptic peptide masses from the database was performed with Peptident proteomic tools in the ExPASy Molecular Biology Server (http:/ / www.expasy.ch/). The SWISS-PROT database was searched within a mass tolerance of $\pm 100 \mathrm{ppm}$ for human proteins; one missed cleavage was allowed. The alkylation of a cysteine residue and the oxidation of methionine were considered as modifications. Proteins were evaluated by considering the number of matched tryptic peptides, the percentage coverage of the entire protein sequence, the experimental $M_{r}$, and the experimental $p I$ of the 2DGE-separated protein. 
Table 4. Sequence coverage vs. stain type

\begin{tabular}{lcc}
\hline MALDI & $\begin{array}{c}\text { Sequence } \\
\text { coverage (\%) }\end{array}$ & $\begin{array}{c}\text { No. of } \\
\text { peptides } \\
\text { matched }\end{array}$ \\
\hline \hline Silver & 75 & 8 \\
Stains-all + Silver & 70 & 7 \\
Coomassie blue & 75 & 9 \\
\hline \hline & & No. of \\
ESI & Sequence & peptides \\
\hline \hline Silver & coverage (\%) & matched \\
Stains-all + Silver & 65 & 8 \\
Coomassie blue & 63 & 7 \\
\hline
\end{tabular}

TR spots were from gels stained with silver, Coomassie blue, or stains-all counterstained with silver nitrate. The $1 \mathrm{~h}$ trypsin digests were analyzed with either MALDI, using a wax-coated stainless steel MALDI target plate, or ESI MS $(n=2)$.

\section{Sample Recovery from MALDI Target Plates}

After MALDI MS, $4 \mu \mathrm{L} 0.1 \%$ TFA was applied onto the dried spot of tryptic peptides on the MALDI target plate; that volume was pipetted up and down twice, and was transferred to a $0.6 \mathrm{~mL}$ siliconized polypropylene microcentrifuge tube. That process was repeated twice with $4 \mu \mathrm{L} 0.1 \%$ TFA; the samples were pooled, and were purified with the ZipTip as described earlier. The pooled eluate $(16 \mu \mathrm{L})$ was concentrated to ca. $4 \mu \mathrm{L}$ in a vacuum centrifuge (ca. $6 \mathrm{~min}$ ), and the concentrate was stored $\left(4^{\circ} \mathrm{C}\right)$ until analyzed with ESI MS within $24 \mathrm{~h}$, or it was stored at $-20^{\circ} \mathrm{C}$ for longer times. Tryptic peptides have been recovered after mass fingerprinting, were used for a sulfonation reaction, and were reanalyzed by MALDI post-source decay MS [27].

\section{LC MS Sample and Analysis}

In-gel tryptic peptides were purified with a ZipTip as described above. The tryptic peptides were analyzed with a Finnigan LCQ Deca ion-trap mass spectrometer

Table 5. Comparison of nine stained and destained protein spots

\begin{tabular}{lrr}
\hline Protein & Stained gel & Destained gel \\
\hline \hline Transthyretin & $11 \pm 0 / 82 \pm 0$ & $9 \pm 1 / 73 \pm 8$ \\
Apolipoprotein A-I & $13 \pm 1 / 52 \pm 3$ & $9 \pm 4 / 50 \pm 8$ \\
Apolipoprotein A-IV & $19 \pm 0 / 46 \pm 2$ & $10 \pm 3 / 28 \pm 7$ \\
Serum albumin (1) & $17 \pm 1 / 34 \pm 2$ & $17 \pm 1 / 35 \pm 3$ \\
Serine/Threonine & $6 \pm 0 / 12 \pm 0$ & $5 \pm 1 / 11 \pm 1$ \\
$\quad$ protein phosphatase & & \\
$\begin{array}{l}\alpha-1 \text { Antitrypsin } \\
\text { Hemopexin }\end{array}$ & $11 \pm 3 / 42 \pm 7$ & $11 \pm 1 / 34 \pm 5$ \\
Serum albumin (2) & $12 \pm 1 / 31 \pm 2$ & $10 \pm 1 / 27 \pm 2$ \\
Serotransferrin & $34 \pm 1 / 59 \pm 3$ & $28 \pm 1 / 53 \pm 2$ \\
& $35 \pm 1 / 56 \pm 3$ & $22 \pm 5 / 39 \pm 7$ \\
\hline
\end{tabular}

No. of peptides matched/\% protein sequence coverage.

The stained and destained protein spots from silver-stained 2-D gels were in-gel trypsin digested $1 \mathrm{~h}$, and the peptides were analyzed with MALDI-TOF MS on a wax-coated stainless steel target plate (Mean \pm s.d., $n=3-5)$.
(ThermoFinnigan Corporation, San Jose, CA) equipped with a nanoESI interface and an in-house packed microcapillary column (PicoFrit; New Objectives, Woburn, MA). The microcapillary column $(75 \mu \mathrm{m}$ i.d. $\times$ $360 \mu \mathrm{m}$ o.d.) was packed with $10.5 \mathrm{~cm}$ of $5 \mu \mathrm{m}$ MagicC18 AQ particles (Michrom BioResources, Inc., Auburn, CA). The tryptic peptide solution $(4 \mu \mathrm{L})$ was loaded onto the column, and the column eluate was sprayed directly into the ESI source. The mobile phase A was ACN/water (2:98 vol/vol) $0.1 \%$ formic acid, and mobile phase B was ACN/water (90:10 vol/vol) $0.1 \%$ formic acid. A linear gradient program, from 0 to $80 \%$ of B over a period of $15 \mathrm{~min}$ (flow-rate $5 \mu \mathrm{L} / \mathrm{min}$ ) was used. The LCQ Deca was operated in a data-dependent scan mode in which a MS scan produced three MS/MS scans. The MS/MS spectra were analyzed with the SEQUEST (Revision 2.0) computer program (ThermoFinnigan Corporation), which correlated the experimental data with the theoretical spectra that are generated from known protein sequences.

\section{Results and Discussion}

The nine protein spots that were excised from stained 2-D gels for this study are shown in Figure 1.

\section{Evaluation of Time Adequate for In-Gel Trypsin Digestion of Protein}

The in-gel trypsin digestion of TR and serum albumin spots from replicate silver-stained gels at different times (10 min to overnight) showed no difference in the percentage of protein sequence coverage and the number of peptides (Table 1). For the TR, the highest sequence coverage was obtained at $1 \mathrm{~h}$. Because TR and serum albumin were characterized for each trypsin digestion time, it was not necessary to carry out an in-gel digestion for more than $2 \mathrm{~h}$.

\section{A Comparison of Stained and Destained Gel Plugs Prior to Trypsin Digestion}

TR spots from replicates of silver-stained gels were in-gel trypsin digested (overnight), and the tryptic peptides were analyzed with MS (MALDI, ESI). The data showed no significant difference in the sequence coverage between the stained and destained gel pieces (Table 2). Replicate experiments produced similar results.

Nine different spots were excised from silver-stained 2-D gels, in-gel trypsin digested for $1 \mathrm{~h}$ or overnight (18 h) and were analyzed with MALDI. There was no difference in the percentage of protein sequence coverage for apolipoprotein A-IV, serum albumin, $\alpha-1$ antitrypsin, and serotransferrin (Table 3 ). However, there was a decrease in the number of tryptic peptides and protein sequence coverage for TR, apolipoprotein A-I, serine/threonine protein phosphatase, and hemopexin 

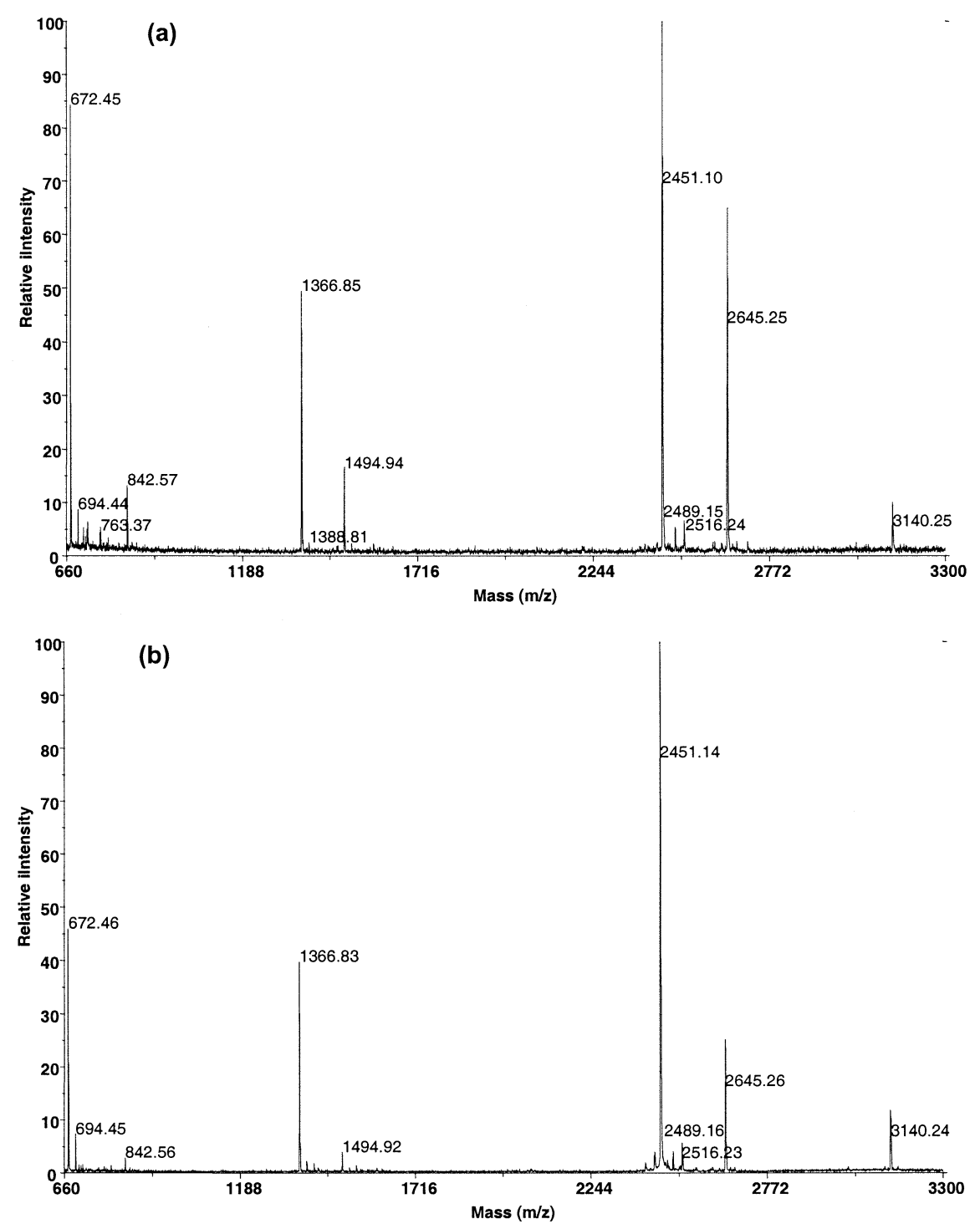

Figure 3. MALDI spectra obtained from stained (a) and destained (b) TR spot.

after $18 \mathrm{~h}$ digestion compared to $1 \mathrm{~h}$. The MALDI spectra for the $1 \mathrm{~h}$ and overnight in-gel digestion of TR samples are shown in Figure 2. The relative intensity of the peaks at $m / z 2645.3,1494.91$, and 905.71 were higher in the $1 \mathrm{~h}$, compared to the overnight, in-gel digestion sample. The relative intensities of the different peptide signals may be due the further digestion of those peptides by trypsin during the prolonged (overnight) incubation, giving rise to smaller peptide fragments. The sequences of the tryptic peptides obtained after a database search show that the peptide at $\mathrm{m} / \mathrm{z} 2645.3$ has two missed cleavages, and may undergo further digestion by trypsin to give rise to ions at $m / z 2516.25,2489$, or 2360. Also, $m / z$ 1494.91, which has one missed cleavage, can undergo further digestion with prolonged incubation with trypsin to give an ion at $m / z 1366.83$. The decrease in the protein coverage was commonly observed with those spots that contained smaller amounts of protein (based on size and intensity of stained spot).

The compatibility of the three differently stained 2-D gels with MALDI-TOF and LC MS was evaluated. The TR spot excised from gels stained with silver, Coomassie blue, or Stains-All counterstained with silver nitrate were identified with MALDI-TOF and ESI MS (Table 4). Replicate experiments produced similar results.

The characterization of the above destained nine different protein spots was compared between stained and destained spots. The excised spots were in-gel digested, and were analyzed with MALDI-TOF MS. There was no difference between the destained and the stained gel data in terms of the number of peptides and the percentage of protein sequence coverage for serum albumin no. 1, serine/threonine protein phosphatase, $\alpha-1$ antitrypsin, and hemopexin (Table 5). The MALDI spectra for the tryptic peptide mixture from TR and 

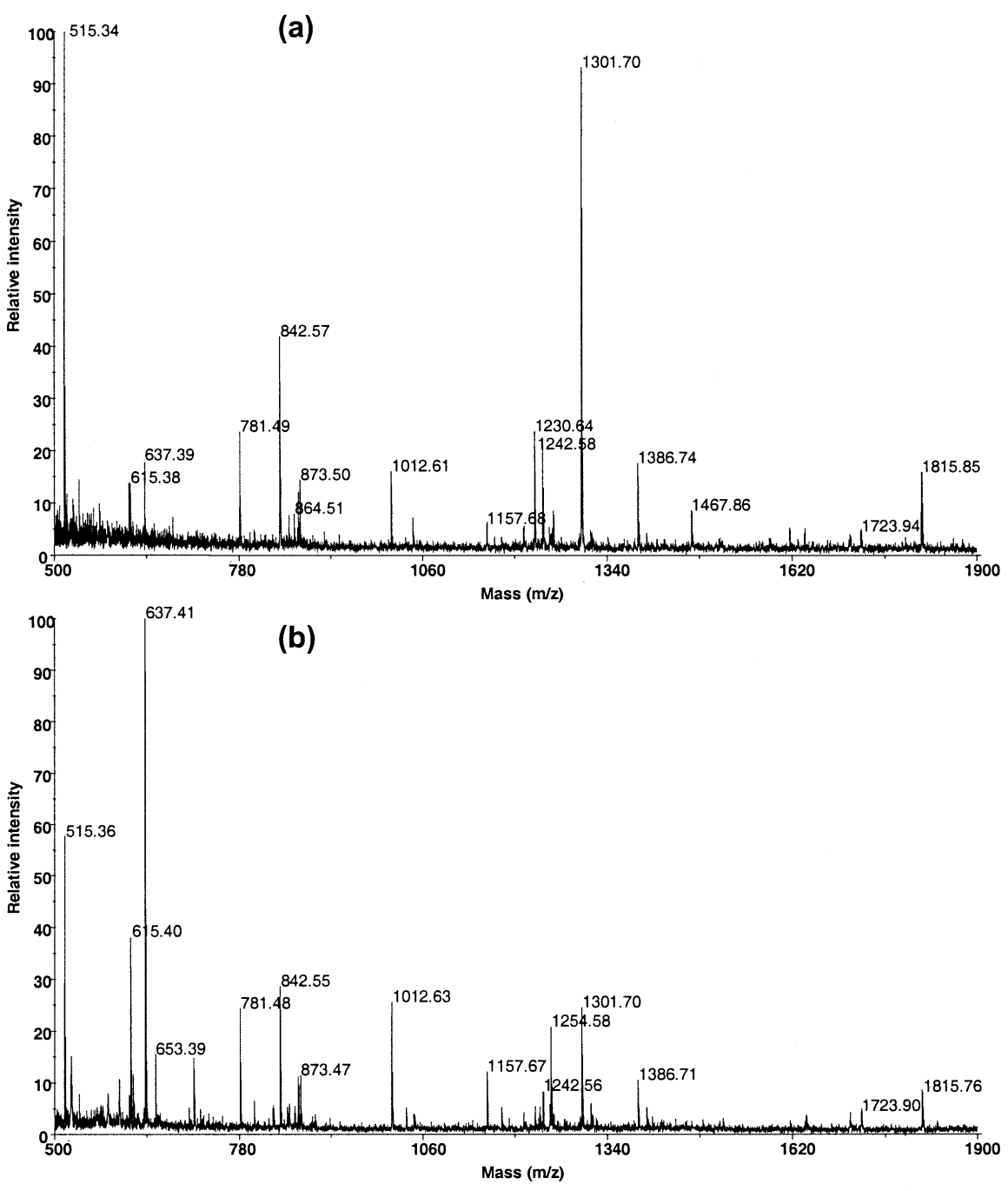

Figure 4. MALDI spectra obtained from stained (a) and destained (b) apolipoprotein A-I spot.

apolipoprotein A-I are shown in Figures 3 and 4, respectively. The dramatic decrease observed in the relative intensities of the different peptide signals for the destained gel plugs may be due to the loss of protein during the process of destaining. Destaining involved an incubation of gel plugs with a destain solution (30 $\mathrm{mM}$ potassium ferricyanide and $100 \mathrm{mM}$ sodium thiosulfate) and several washings with water, and may have led to a leaching-out of the gel plugs water-soluble (hydrophilic) proteins, resulting in some loss in the amount of those proteins. In addition, proteins that have the tendency to refold may be soluble. Therefore, initiating an in-gel trypsin digestion with a smaller amount of protein may result in lower relative intensities of some of the peptide signals.

\section{Comparison of Three Different MALDI Target Surfaces}

Three different MALDI target plate surfaces (AnchorChip, wax-coated stainless steel, and stainless MALDI plates) were compared. There was no difference in the number of peptides and the percentage of sequence coverage for the three different target plates (Table 6). The AnchorChip provides no advantage over the waxcoated stainless steel MALDI target plate in the identification of proteins, provided that the correct concentration of CHCA solution is used. The wax-coated

Table 6. Three different MALDI target plate surfaces

\begin{tabular}{lccc}
\hline $\begin{array}{l}\text { Transthyretin } \\
\text { dilution }\end{array}$ & $\begin{array}{c}\text { AnchorChip } \\
\text { plate }\end{array}$ & $\begin{array}{c}\text { Wax-coated } \\
\text { stainless } \\
\text { steel plate }\end{array}$ & $\begin{array}{c}\text { Stainless } \\
\text { steel plate }\end{array}$ \\
\hline \hline Stock & $10 \pm 0 / 75 \pm 0$ & $10 \pm 0 / 75 \pm 0$ & $10 \pm 0 / 75 \pm 0$ \\
$1 / 2$ & $10 \pm 0 / 73 \pm 2$ & $10 \pm 0 / 73 \pm 2$ & $9 \pm 0 / 72 \pm 2$ \\
$1 / 5$ & $4 \pm 0 / 34 \pm 0$ & $6 \pm 1 / 61 \pm 4$ & $4 \pm 0 / 34 \pm 0$ \\
$1 / 10$ & $3 \pm 0 / 16 \pm 0$ & $4 \pm 0 / 28 \pm 6$ & $3 \pm 0 / 16 \pm 0$ \\
$1 / 50$ & $1 \pm 0 / 5 \pm 0$ & $1 \pm 0 / 5 \pm 0$ & 0 \\
& & &
\end{tabular}

No. peptides/\% protein coverage.

The same TR gel spot pool was diluted and analyzed on three different MALDI target plate surfaces. Mean \pm s.d., $n=3$. 

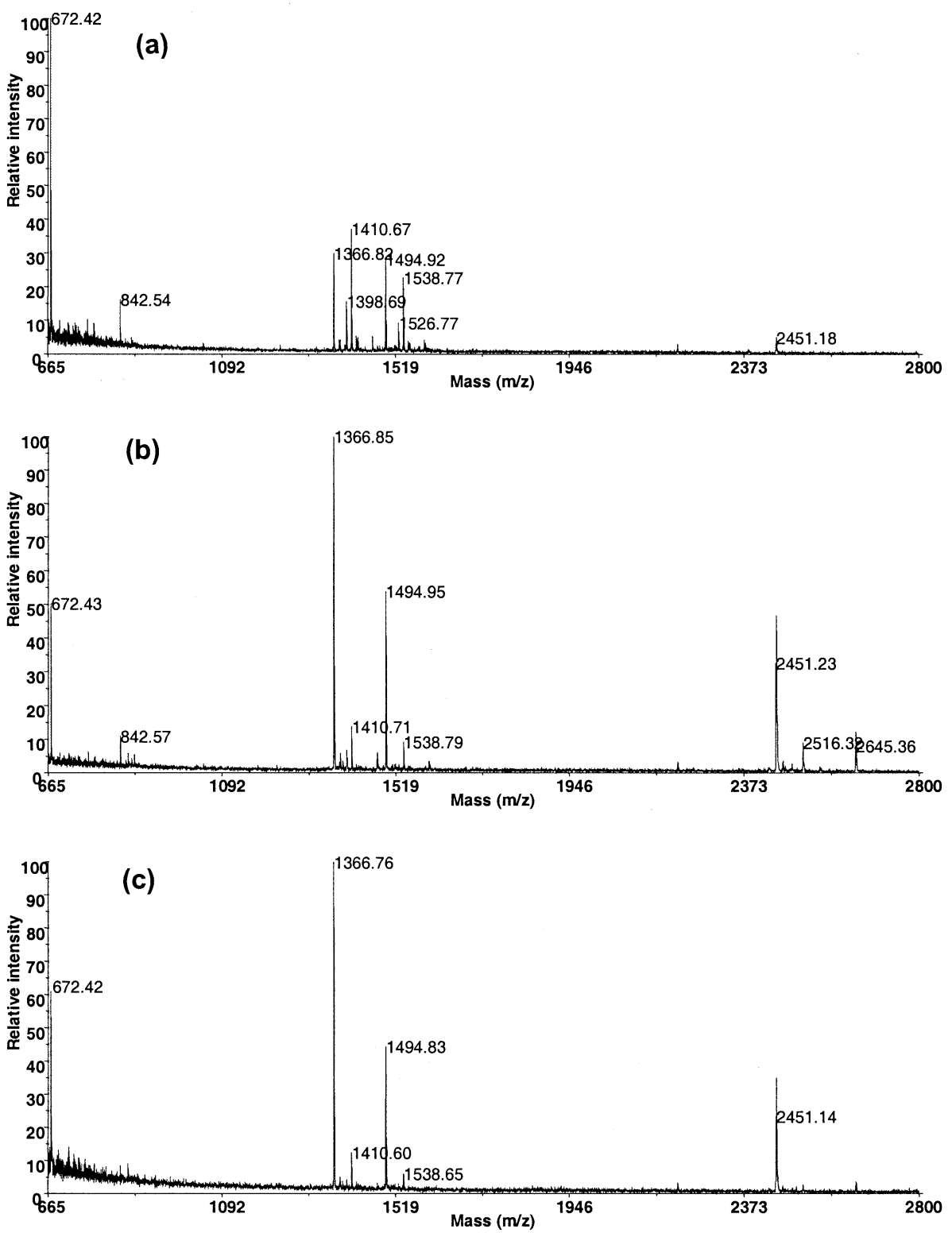

Figure 5. Comparsion of a tryptic digest on three different MALDI target plate surfaces. A pool of TR protein spots (4 silver-stained 2-D gels) was in-gel trypsin digested for $1 \mathrm{~h}$. The extracted tryptic peptides were ZipTip-purified, and were concentrated (to $30 \mu \mathrm{L}$; referred to as stock). The stock TR was diluted 1/5, and was analyzed on either an AnchorChip (a), wax-coated stainless steel (b), or stainless steel (c) MALDI target plate. Note that the trypsin autodigestion peak $(\mathrm{m} / \mathrm{z}$ 842.51) is absent on the stainless steel target plate.

MALDI target plate provided an increased detection sensitivity, especially at low peptide concentrations (1/5 and $1 / 10$ TR stock dilutions). At the $1 / 5$ and $1 / 10$ TR dilutions, the number of peptides and the percentage of protein sequence coverage were the highest with the wax-coated stainless steel plate compared to the AnchorChip and stainless steel MALDI target plates. At the $1 / 50$ TR dilution, only one peptide was identified for the AnchorChip and wax-coated stainless steel MALDI target plates, and none for the stainless steel MALDI target plate. The MALDI spectra for the 1/5diluted TR tryptic peptides spotted onto the three different MALDI target plates showed two peptide peaks $(\mathrm{m} / \mathrm{z} 2517.32$ and 2645.36) that were present in only the wax-coated stainless steel MALDI target plate (Figure 5). The calculated hydrophobicity, using a scale for the relative hydrophobicity of amino acids [28], for the tryptic peptides at $\mathrm{m} / \mathrm{z} 2517.32$ and 2645.36 are -4 and -13.9 , respectively. The absence of those two tryptic peptides in the AnchorChip and stainless steel plates may not be due to the hydrophobicity, because other tryptic peptides at $\mathrm{m} / \mathrm{z} 1366.82$ and 1410.67 are -4 . A trypsin autodigestion peak $(\mathrm{m} / \mathrm{z}$ 842.51) was present in the AnchorChip and wax-coated stainless steel 

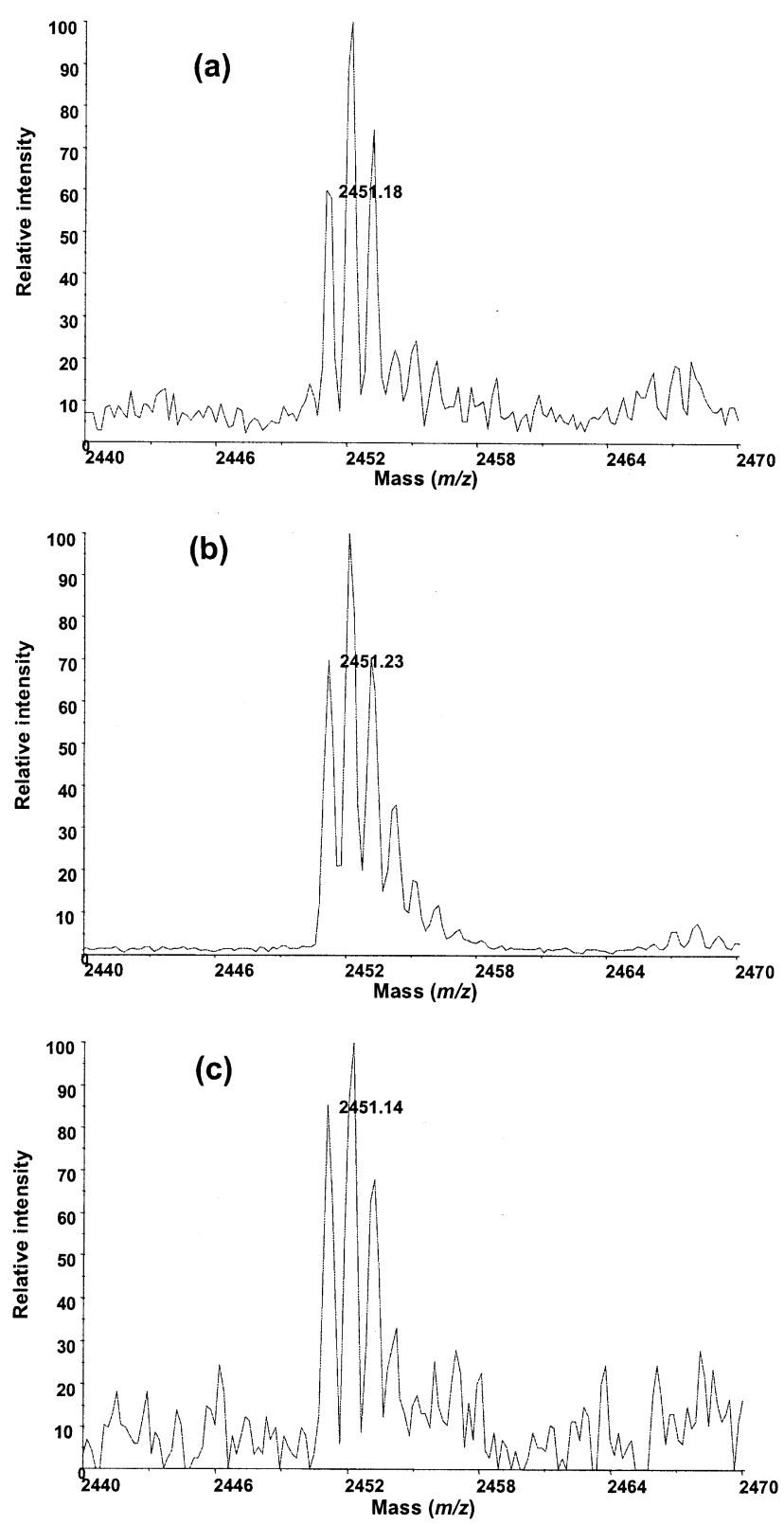

Figure 6. Quality of MALDI spectra with different MALDI target plates. The spectra of a selected TR tryptic peptide $(\mathrm{m} / \mathrm{z} 2451.21)$ obtained from the MALDI-TOF MS analysis of 1/5-diluted TR tryptic peptides spotted onto either an AnchorChip (a), waxcoated stainless steel (b), or stainless steel (c) MALDI target plate.

plates, but not the stainless steel MALDI target plate. The signal/noise ratio of the TR peptide peak $\mathrm{m} / \mathrm{z}$ 2451.21 was best with the wax-coated stainless steel MALDI target plate (Figure 6). One of the more striking features of the waxed plate was the increase in the signal/noise ratio. The highest percentage of proteinsequence coverage obtained with the wax-coated stainless steel plate compared to the AnchorChip and stainless steel MALDI target plates could be due to the fact that the wax-coated stainless steel MALDI target plate concentrates the spotted sample ca. $2 \times$ more than the other conventional target plates (AnchorChip and stain-
Table 7. Recovery of tryptic peptides from three different MALDI target plates

\begin{tabular}{lccc}
\hline MALDI & $\begin{array}{c}\text { AnchorChip } \\
\text { plate }\end{array}$ & $\begin{array}{c}\text { Wax-coated } \\
\text { stainless } \\
\text { steel plate }\end{array}$ & $\begin{array}{c}\text { Stainless } \\
\text { steel plate }\end{array}$ \\
\hline \hline Transthyretin & $10 \pm 0 / 75 \pm 0$ & $10 \pm 0 / 75 \pm 0$ & $10 \pm 0 / 75 \pm 0$ \\
$\begin{array}{l}\text { Serum albumin } \\
\text { Apolipoprotein } \\
\text { A-I }\end{array}$ & $11 \pm 1 / 37 \pm 2$ & $22 \pm 0 / 36 \pm 0$ & $16 \pm 2 / 27 \pm 1$ \\
& & & \\
\hline \hline & & Wax-coated & \\
ESI & AnchorChip & stainless & Stainless \\
plate & steel plate & steel plate \\
\hline \hline Transthyretin & $7 \pm 1 / 69 \pm 7$ & $8 \pm 1 / 72 \pm 9$ & $5 \pm 1 / 60 \pm 7$ \\
Serum albumin & $15 \pm 1 / 23 \pm 3$ & $14 \pm 1 / 21 \pm 1$ & $12 \pm 1 / 18 \pm 1$ \\
Apolipoprotein & $10 \pm 2 / 38 \pm 6$ & $13 \pm 2 / 48 \pm 10$ & $9 \pm 2 / 33 \pm 4$ \\
A-I & & & \\
\hline
\end{tabular}

No. peptides $/ \%$ protein coverage.

The tryptic peptide samples were analyzed with MALDI MS, were recovered from the MALDI target plate, and were analyzed with ESI MS. Mean \pm s.d., $n=3$.

less steel MALDI target plates). Two microliters of sample eluted from the ZipTip and spotted onto the AnchorChip, wax-coated stainless steel, or stainless steel MALDI target plate gave 2, 1.25, and $3 \mathrm{~mm}$ dried spot size, respectively.

\section{Tryptic Peptide Recovery from MALDI Target}

The recovery of tryptic peptides from the three different types of MALDI target plates (AnchorChip, wax-coated stainless steel, stainless steel) was evaluated. Three protein spots (TR, serum albumin, and apolipoprotein A-I) from silver-stained 2-D gels were in-gel trypsin digested $(1 \mathrm{~h})$. The tryptic peptides were analyzed with MALDI-TOF MS, using AnchorChip, wax-coated stainless steel, or stainless steel MALDI target plates. Thereafter, the tryptic peptides were recovered and analyzed with ESI MS (Table 7); the proteins were characterized. This combined strategy could readily be employed for unknown and unidentified samples from MALDI-TOF MS because the sample can be analyzed subsequently with ESI MS to obtain amino acid sequence data.

\section{Conclusion}

A wax-coated stainless steel MALDI target plate improved the quality of the MALDI spectra, and is also less costly compared with an AnchorChip target plate. It is not necessary to destain 2-D gel pieces prior to an in-gel enzyme digestion, and tryptic peptides can be recovered from a MALDI target plate for LC MS/MS to obtain amino acid sequence data. Improved protein identification sensitivity and a reduction in sampleprocessing time are of particular benefit to the characterization of low-abundance proteins, and for a costeffective, high-throughput system. 


\section{Acknowledgments}

The authors thank NIH and NSF (to DMD) for their financial support: (DA12212), MALDI-TOF mass spectrometer (NIH RR 10522 and NSF DBI 9604633), and LCQ ${ }^{\text {DECA }}$ (NIH RR 14593).

\section{References}

1. Gharahdaghi, F.; Weinberg, C. R.; Meagher, D. A.; Imai, B. S.; Mische, S. M. Mass Spectrometric Identification of Proteins from Silver-Stained Polyacrylamide Gel: A Method for the Removal of Silver Ions to Enhance Sensitivity. Electrophoresis 1999, 20, 601-605.

2. Raymackers, J.; Daniels, A.; De Brabandere, V.; Missiaen, C.; Dauwe, M.; Verhaert, P.; Vanmechelen, E.; Meheus, L. Identification of Two-Dimensionally Separated Human Cerebrospinal Fluid Proteins by N-Terminal Sequencing, Matrix-Assisted Laser Desorption/Ionization-Mass Spectrometry, Nanoliquid Chromatography-Electrospray Ionization-Time-of-Flight Mass Spectrometry, and Tandem Mass Spectrometry. Electrophoresis 2000, 21, 2266-2283.

3. Lauber, W. M.; Carroll, J. A.; Dufield, D. R.; Kiesel, J. R.; Radabaugh, M. R.; Malone, J. P. Mass Spectrometry Compatibility of Two-Dimensional Gel Protein Stains. Electrophoresis 2001, 22, 906-918.

4. Yuan, X.; Desiderio, D. M. Protein Identification with Teflon as Matrix-Assisted Laser Desorption/Ionization Sample Support. J. Mass Spectrom. 2002, 37, 512-524.

5. Sickmann, A.; Dormeyer, W.; Wortelkamp, S.; Woitalla, D.; Kuhn, W.; Meyer, H. E. Identification of Proteins from Human Cerebrospinal Fluid, Separated by Two-Dimensional Polyacrylamide Gel Electrophoresis. Electrophoresis 2000, 21, 27212728.

6. Isfort, R. J.; Wang, F.; Greis, K. D.; Sun, Y.; Keough, T. W.; Farrar, R. P.; Bodine, S. C.; Anderson, N. L. Proteomic Analysis of Rat Soleus Muscle Undergoing Hindlimb SuspensionInduced Atrophy and Reweighting Hypertrophy. Proteomics 2002, 2, 543-550.

7. Pluskal, M. G.; Bogdanova, A.; Lopez, M.; Gutierrez, S.; Pitt, A. M. Multiwell In-Gel Protein Digestion and Microscale Sample Preparation for Protein Identification by Mass Spectrometry. Proteomics 2002, 2, 145-150.

8. Mineki, R.; Taka, H.; Fujimura, T.; Kikkawa, M.; Shindo, N.; Murayama, K. In Situ Alkylation with Acrylamide for Identification of Cysteinyl Residues in Proteins During One- and Two-Dimensional Sodium Dodecyl Sulphate-Polyacrylamide Gel Electrophoresis. Proteomics 2002, 2, 1672-1681.

9. Tie, J. K.; Mutucumarana, V. P.; Straight, D. L.; Carrick, K. L.; Pope, R. M.; Stafford, D. W. Determination of Disulfide Bond Assignment of Human Vitamin K-Dependent $\{\gamma\}$-Glutamyl Carboxylase by Matrix-Assisted Laser Desorption/Ionization Time-of-Flight Mass Spectrometry. J. Biol. Chem. 2003, 278, $45468-45475$.

10. Keough, T.; Lacey, M. P.; Fieno, A. M.; Grant, R. A.; Sun, Y.; Bauer, M. D.; Begley, K. B. Tandem Mass Spectrometry Methods for Definitive Protein Identification in Proteomics Research. Electrophoresis 2000, 21, 2252-2265.

11. Pang, L.; Fryksdale, B. G.; Chow, N.; Wong, D. L.; Gaertner, A. L.; Miller, B. S. Impact of Prefractionation Uusing Gradiflow Trade Mark on Two-Dimensional Gel Electrophoresis and Protein Identification by Matrix Assisted Laser Desorption/Ionization Time-of-Flight-Mass Spectrometry. Electrophoresis 2003, 24, 3484-3492.

12. Davidsson, P.; Folkesson, S.; Christiansson, M.; Lindbjer, M.; Dellheden, B.; Blennow, K.; Westman-Brinkmalm, A. Identification of Proteins in Human Cerebrospinal Fluid Using Liq-
uid-Phase Isoelectric Focusing as a Prefractionation Step Followed by Two-Dimensional Gel Electrophoresis and MatrixAssisted Laser Desorption/Ionization Mass Spectrometry. Rapid Commun. Mass Spectrom. 2002, 16, 2083-2088.

13. Sickmann, A.; Dormeyer, W.; Wortelkamp, S.; Woitalla, D.; Kuhn, W.; Meyer, H. E. Towards a High Resolution Separation of Human Cerebrospinal Fluid. J. Chromatogr. B Anal. Technol. Biomed. Life Sci. 2002, 71, 167-196.

14. Lopez, M. F.; Berggren, K.; Chernokalskaya, E.; Lazarev, A.; Robinson, M.; Patton, W. F. A Comparison of Silver Stain and SYPRO Ruby Protein Gel Stain with Respect to Protein Detection in Two-Dimensional Gels and Identification by Peptide Mass Profiling. Electrophoresis 2000, 21, 3673-3683.

15. Parker, K. C.; Garrels, J. I.; Hines, W.; Butler, E. M.; McKee, A. H.; Patterson, D.; Martin, S. Identification of Yeast Proteins from Two-Dimensional Gels: Working Out Spot Cross-Contamination. Electrophoresis 1998, 19, 1920-1932.

16. Wilm, M.; Mann, M. Analytical Properties of the Nanoelectrospray Ion Source. Anal. Chem. 1996, 68, 1-8.

17. Hung, K. C.; Ding, H.; Guo, B. Use of Poly(Tetrafluoroethylene)s as a Sample Support for the MALDI-TOF Analysis of DNA and Proteins. Anal. Chem. 1999, 71, 518-521.

18. Schuerenberg, M.; Luebbert, C.; Eickhoff, H.; Kalkum, M.; Lehrach, H.; Nordhoff, E. Prestructured MALDI-MS Sample Supports. Anal. Chem. 2000, 72, 3436-3442.

19. Botting, C. H. Improved Detection of Higher Molecular Weight Proteins by Matrix-Assisted Laser Desorption/Ionization Time-of-Flight Mass Spectrometry on Polytetrafluoroethylene Surfaces. Rapid Commun. Mass Spectrom. 2003, 17, 598602.

20. McComb, M. E.; Oleschuk, R. D.; Chow, A.; Ens, W.; Standing, K. G.; Perreault, H.; Smith, M. Characterization of Hemoglobin Variants by MALDI-TOF MS Using a Polyurethane Membrane as the Sample Support. Anal. Chem. 1998, 70, 5142-5149.

21. Hung, K. C.; Rashidzadeh, H.; Wang, Y.; Guo, B. Use of Paraffin Wax Film in MALDI-TOF Analysis of DNA. Anal. Chem. 1998, 70, 3088-3093.

22. Worrall, T. A.; Cotter, R. J.; Woods, A. S. Purification of Contaminated Peptides and Proteins on Synthetic Membrane Surfaces for Matrix-Assisted Laser Desorption/Ionization Mass Spectrometry. Anal. Chem. 1998, 70, 750-756.

23. Bradford, M. M. A Rapid and Sensitive Method for the Quantitation of Microgram Quantities of Protein Utilizing the Principle of Protein-Dye Binding. Anal. Biochem. 1976, 72, 248-254.

24. Pharmacia Biotech Silver Staining Kit Protein Instruction; 717177-00 Edition AE.

25. Goldberg, H. A.; Warner, K. J. The Staining of Acidic Proteins on Polyacrylamide Gels: Enhanced Sensitivity and Stability of "Stains-All" Staining in Combination with Silver Nitrate. Anal. Biochem. 1997, 251, 227-233.

26. Erdjument-Bromage, H.; Lui, M.; Lacomis, L.; Grewal, A.; Annan, R. S.; McNulty, D. E.; Carr, S. A.; Tempst, P. Examination of Micro-Tip Reversed-Phase Liquid Chromatographic Extraction of Peptide Pools for Mass Spectrometric Analysis. J. Chromatogr. A 1998, 826, 167-181.

27. Keough, T.; Lacey, M. P.; Youngquist, R. S. Solid-Phase Derivatization of Tryptic Peptides for Rapid Protein Identification by Matrix-Assisted Laser Desorption/Ionization Mass Spectrometry. Rapid Commun. Mass. Spectrom. 2002, 16, 10031015.

28. Schultz, R. M.; Liebman, M. N. Proteins: Composition and Structure. In Textbook of Biochemistry with Clinical Correlations, 3rd ed.; Devlin, T. M., Ed.; Wiley-Liss, Inc.: New York, 1992; Chap II, pp 25-90. 